\title{
(2) OPEN ACCESS \\ Prevention in the age of personal responsibility: epigenetic risk-predictive screening for female cancers as a case study
}

\author{
Ineke Bolt, ${ }^{1}$ Eline M. Bunnik, ${ }^{1}$ Krista Tromp, ${ }^{1}$ Nora Pashayan, ${ }^{2}$ Martin Widschwendter, ${ }^{3}$ \\ Inez de Beaufort ${ }^{1}$
}

'Department of Medical

Ethics, Philosophy and History of Medicine, Erasmus MC Rotterdam, The Netherlands ${ }^{2}$ UCL Department of Applied Health Research, University College London, London, UK ${ }^{3}$ Department of Women's Cancer, University College London, London, UK

\section{Correspondence to}

Dr Ineke Bolt, Department of Medical Ethics, Philosophy and History of Medicine, Erasmus MC, Rotterdam 3000 CA, The Netherlands;

L.Bolt@erasmusmc.n

Received 14 February 2020 Revised 18 August 2020 Accepted 23 August 2020

\section{Check for updates}

(C) Author(s) (or their employer(s)) 2020. Re-use permitted under CC BY-NC. No commercial re-use. See rights and permissions. Published by BMJ.

To cite: Bolt I, Bunnik EM, Tromp K, et al. J Med Ethics Epub ahead of print: [please include Day Month Year]. doi:10.1136/

medethics-2020-106146

\section{ABSTRACT}

Epigenetic markers could potentially be used for risk assessment in risk-stratified population-based cancer screening programmes. Whereas current screening programmes generally aim to detect existing cancer, epigenetic markers could be used to provide risk estimates for not-yet-existing cancers. Epigenetic riskpredictive tests may thus allow for new opportunities for risk assessment for developing cancer in the future. Since epigenetic changes are presumed to be modifiable, preventive measures, such as lifestyle modification, could be used to reduce the risk of cancer. Moreover, epigenetic markers might be used to monitor the response to risk-reducing interventions. In this article, we address ethical concerns related to personal responsibility raised by epigenetic risk-predictive tests in cancer population screening. Will individuals increasingly be held responsible for their health, that is, will they be held accountable for bad health outcomes? Will they be blamed or subject to moral sanctions? We will illustrate these ethical concerns by means of a Europewide research programme that develops an epigenetic risk-predictive test for female cancers. Subsequently, we investigate when we can hold someone responsible for her actions. We argue that the standard conception of personal responsibility does not provide an appropriate framework to address these concerns. A different, prospective account of responsibility meets part of our concerns, that is, concerns about inequality of opportunities, but does not meet all our concerns about personal responsibility. We argue that even if someone is responsible on grounds of a negative and/or prospective account of responsibility, there may be moral and practical reasons to abstain from moral sanctions.

\section{INTRODUCTION}

Over the past decade, efforts have been made to transform medicine from reactive-acting on symptoms with medical care and/or treatment- to a healthcare approach that is referred to as P4 Medicine: preventive, predictive, personalised and participatory. ${ }^{1}$ Currently, international and European consortia are engaged in research aligned with the vision of P4 Medicine. Advances in computational and biomedical sciences allow for the development of omics-based tests. Based on the characterisation of sets of biological molecules such as DNA, RNA, epigenetic mechanisms, proteins, microbes and metabolites, 'omics'-based tests could be used to predict the risks of individuals for specific diseases such as cancer and dementia. ${ }^{1}$ Among the 'omics' disciplines, epigenomics, in particular, has emerged as a promising field. ${ }^{2}{ }^{3}$ Epigenomics is the study of the complete set of epigenetic modifications in a cell. Epigenetics refers to molecular mechanisms that affect the regulation of gene expression without altering the DNA sequence.

Epigenomics has three morally relevant distinguishing features. First, epigenetic changes may result from environmental exposures, for example, pollution, (early life) stress, physical exercise, diet and smoking. ${ }^{5}$ Consequently, epigenetic data may potentially reveal sensitive information about a person's past lifestyle and exposures. Second, it is, in part, hereditary: epigenetic modifications can be passed on to next generation(s). ${ }^{i}$ Finally, unlike genetic mutations, epigenetics may change over time and is, in theory, modifiable or reversible; epigenetic changes may be modulated, for example, by diet, drugs, healthy behaviour and other environmental factors. ${ }^{6}$

One of the best-studied epigenetic mechanisms is DNA methylation, a process in which methyl groups are added to parts of the DNA thereby affecting transcription. ${ }^{7}$ New assays developed for the identification of markers of DNA methylation can provide insight into its role in the pathogenesis of cancer-through silencing of tumour suppressor genes and/or activation of oncogenes ${ }^{8}$ - and other diseases. Also, they can be used in (more precise) diagnosing or staging of cancer types and personalised treatment. Furthermore, as epigenetic markers may indicate one's future risk of developing certain types of cancer, epigenetic tests may be used in screening of healthy individuals. Epigenetic riskpredictive cancer tests could thus be implemented in public health settings to improve populationbased screening programmes. ${ }^{\text {ii }}$

Implementation of epigenetic risk-predictive cancers tests in population-based screening (in short, epigenetic screening) raises ethical concerns, ranging from issues involving the feasibility of informed consent (eg, the capacity of citizens to understand complex information about risks for multiple diseases) ${ }^{9}$ to issues related to big data

\footnotetext{
${ }^{\mathrm{i}}$ More studies are needed to confirm the transgenerational effect. ${ }^{39}$ We will not discuss the transgenerational effect since our focus is on the implementation of epigenetic screening and personal responsibility. ${ }^{i i}$ Epigenetic mechanisms also play a role in other diseases and contexts (eg, the potential transmission of epigenetic risks from parent to child and on the child's future health, see M'hamdi). ${ }^{40}$
} 
and privacy ${ }^{10}$ and to medicalisation and reconceptualisation of disease. ${ }^{11} 12$ iii In this paper, we focus on a different issue: the effects of introducing epigenetic screening on the tendency within societies to hold individuals responsible for their health, potentially leading to blaming the victim, stigmatisation and discrimination. ${ }^{12-16}$ By personal responsibility, we mean: a responsibility for which an individual might be held accountable in the sense of being treated differently and/or blamed and/or in the allocation of healthcare resources.

This is one of the major ethical concerns discussed in the literature on advances in epigenetics. May individuals increasingly be held responsible for their health now that technology increases opportunities to reduce cancer risks? Ought we hold individuals accountable if they are known to have a high risk of cancer but do not change their lifestyle nor comply with the offered personalised screening interventions? Are healthcare professionals allowed (or obliged) to steer these individuals or put them under pressure (eg, using praise or blame) to change their lifestyle or undergo screening or preventive measures? Is it morally acceptable if these individuals have to pay higher health premiums or to exclude them from reimbursement through collective funds?

In order to discuss these questions, we introduce a case study of potential implementation of epigenetic risk-predictive female cancer tests in the context of a population-based screening programme. Next, we provide an inventory of the ethical concerns related to personal responsibility raised by epigenetic screening. Subsequently, we argue that the standard model of personal responsibility may not provide sufficient ethical guidance in how to deal with these concerns and an institutional account of responsibility may provide a promising approach. Finally, we draw attention to a number of points to consider in the responsible implementation of epigenetic screening, that result from our analysis of ethical concerns regarding personal responsibility.

\section{Epigenetic risk-predictive female cancer screening as a case study}

Currently, a research consortium 'Female cancer prediction using cervical omics to individualise screening and prevention' (FORECEE) is examining how epigenetic tests may be implemented for risk stratification in nationwide cancer population screening programmes. FORECEE is developing a multiomics risk-prediction tool to predict women's risk of four female cancers-ovarian, breast, endometrial and cervical-using cervical cells based on epigenetic, genetic and microbiome markers. ${ }^{4}$ iv Whereas current cancer screening programmes, in general, aim to detect existing cancer (eg, breast cancer by using mammography), omics markers could be used to provide risk estimates for not-yet-existing cancers. Multiomics test would provide for new opportunities for risk assessment for developing multiple cancers in the future. Based on the results, a woman's risk for breast, ovarian, endometrial and cervical cancers can be classified into risk groups, for example, low, intermediate

\footnotetext{
${ }^{\text {iii } M e d i c a l i s a t i o n: ~ d u e ~ t o ~ e p i g e n e t i c ~ s c r e e n i n g ~ a ~ n o r m a l ~ h e a l t h y ~}$ state and experiences (stress, eating patterns and so on) or an at-risk state may be perceived, experienced and monitored (by individuals themselves and others) as a potential disease state. An example of overdiagnosis is ductal carcinoma in situ (DCIS). See Hofmann's article on the distinction between medicalisation and overdiagnoses and the P4 systems medicine. ${ }^{41}$

${ }^{\text {iv }}$ Methylation tests are not yet in clinical use, and the riskprediction tool of the project Female cancer prediction using cervical omics to individualise screening and prevention (FORECEE) is still in marker discovery phase.
}

or high. Personalised advice can be offered regarding screening eligibility, start and stop age, and frequency and modality of screening, in other words, a risk-stratified screening approach. ${ }^{17}$

Implementation of nationwide epigenetic risk-predictive population-based cancer screening programmes may have important advantages. Because of its preventive and riskstratified approach, it may reduce overdiagnosis and overtreatment, and hence improve the efficacy of existing early detection population screening programmes (for example, breast cancer screening). ${ }^{17} \mathrm{v}$ Epigenetic risk-predictive population-based cancer screening as such can promote individual autonomy by providing information about an individual's cancer risk and offer options regarding the frequency of screening and preventive management. ${ }^{9} 18$

However, implementation of epigenetic screening also raises ethical concerns related to personal responsibility. Some authors indicate that discussing such ethical issues may be premature given the current limited scientific evidence of the clinical utility of epigenetic tests for risk stratification. ${ }^{10} 16$ Also, it could be argued that these issues are not exactly new and occur in other screening tests for modifiable (eg, lifestyle) risk factors, such as obesity and smoking status, as well. Given the increasing research activity on epigenetic risk-predictive cancer tests and the special salience of epigenetic data, a discussion of the question of its impact on the notion of personal responsibility is timely. We do not mean to suggest that epigenetics data are essentially different, unique or exceptional, ${ }^{16}$ or even that they will be more informative about individuals' risks of developing cancer than are other biomarkers or lifestyle factors. The clinical validity and utility of epigenetic data may be overestimated and their promises may not pan out. However, there are differences between epigenetic data and other types of data that are worth exploring in the context of moral responsibility.

Epigenetic biomarkers are different from other types of biomarkers in that they reflect the combined effects of a person's genetic background and environmental exposures on their health status. Epigenetic biomarkers may thus explain why in some individuals, for example, obesity or smoking or other exposures will result in an increased risk of specific cancers, and why in other individuals, the same lifestyles or exposures will not. Further, unlike genetic changes, epigenetic changes are presumed to be modifiable, which opens opportunities for preventive measures such as lifestyle changes to restore the risk status to a normal state and thus lower the individual's risk of cancer. ${ }^{19}{ }^{20}$ Moreover, epigenetic biomarkers may enable monitoring of the effects of risk-reducing measures. ${ }^{4}$ Individuals could therefore be informed about personalised preventive options, including lifestyle adaptations, that may work to reverse epigenetic modifications and improve risk status. ${ }^{21}$

\footnotetext{
${ }^{\mathrm{V}}$ Overdiagnosis is defined as 'a diagnosis of a condition in a(n asymptomatic) person where the diagnosis does not produce a net benefit for that person'. ${ }^{41}$ In other words, abnormalities detected by screening that meet the definition of cancer but will never lead to cancer symptoms in the expected patient's lifetime. Overdiagnosis can lead to overtreatment, for example, chemotherapy or surgery that provide the patient with no survival benefit but with adverse side effects. Modelling studies have shown that the probability of overdiagnosis is lower in the higher risk groups. Subsequently, risk stratification and targeting screening to higher risk groups would reduce overdiagnosis. ${ }^{42}{ }^{43}$ Hofmann points out that overdiagnosis still exists as a problem in preventive screening. When can a precursor believed to contribute to cancer correctly be defined as (pre)cancer? ${ }^{44}$
} 


\section{Reasons for concern regarding personal responsibility}

In theory, epigenetic tests implemented in population-based screening may provide a real-time understanding of one's risk status, and a clearly visible (traceable) relationship between lifestyle factors and (risk of) disease. This very aspect could motivate people to adopt a healthy lifestyle and make use of preventive interventions. It is, as of yet, unclear whether people (will) in fact do so based on epigenetic risk information; the effect of epigenetic risk-predictive testing for cancer risk on the motivation of individuals to adjust their lifestyle has not been studied. However, research into the effect of communication of DNAbased (ie, genomic or genetic) disease risk estimation shows no or only a small effect on risk-reducing behaviour. ${ }^{22-24}$ Similarly, it is questionable whether offering epigenetic cancer risk information in itself will motivate people to adopt healthy lifestyles. Although, in theory, a high-risk score might be lowered by lifestyle adaptations because of the reversible nature of DNA methylation, changing one's lifestyle is not as simple as it seems, and simpler for some than it is for others.

This concern applies, in particular, to individuals with low health literacy skills. Health literacy consists of four competencies: the ability to gather, understand, appraise and apply health information. ${ }^{25}$ Research shows that socioeconomic status is associated with health literacy. ${ }^{26}{ }^{27}$ Limited health literacy has a negative impact on health outcomes and service use. ${ }^{26}$ When epigenetic tests identify (elevated) risk status, groups with a low socioeconomic status and limited health literacy may not be able to adjust their lifestyle. Hence, they will not reap the potential benefits of screening and may even be held accountable for loss of health because of inability to adjust their lifestyle. This, however, would be unfair. Thus, not only it is unclear whether screening will bring benefit (by leading to healthier lifestyles), any potential benefit to be obtained may also be unequally distributed.

Another concern arises when individuals do possess sufficient health literacy skills, opportunities to reduce risk are available and obstructive factors are non-existent, and may thus become or be held responsible. This occurs, for example, if adequate programmes were offered to support adaptation of healthy behaviour but some individuals with a high risk knowingly and deliberately refrain from a more intense screening regime and/ or healthy lifestyles and prevention management. A recent study into attitudes of European women towards predictive epigenetic risk testing showed that women were generally receptive about epigenetic screening, with the tests' potential for prevention, management and lifestyle changes to be the main reason in favour of the test. Additionally, an increase of (unnecessary) worry about cancer and coercion into the adoption of a healthy lifestyle and healthcare interventions were the main reasons of the surveyed women to disfavour these tests. ${ }^{28}$ Participation in current cancer screening programmes is optional. Although voluntariness should (and will likely) continue to be a formal criterion for responsible screening, non-participation might in the future in both screening for risk as screening for disease elicit 'blaming the victim' (blaming individuals for their health problems), stigmatisation (eg, in daily social interactions, in condemnatory language by healthcare professionals) and/or discrimination (eg, unjust exclusion or hindrances of access to social arrangements, reimbursement of healthcare costs, disability and life insurance and so on). In light of the potential visible and traceable relationship between lifestyle and cancer risk and the reversibility of epigenetic cancer risk, the introduction of epigenomics in population screening may exacerbate these ethical concerns.
Finally, there is a tension between the broader societal shift to personal responsibility of individuals for their own health and one of the distinguishing features of epigenetics, namely the effects of environmental factors on epigenetic processes. ${ }^{12} 141529$ Who ought to be held responsible for the detrimental effects on a person's health caused by environmental pollution or unhealthy work-conditions? For healthcare systems, it may be easier and more efficient to treat the detrimental health effects in individual patients than to tackle environmental causal factors. The setting up of epigenetic screening programmes offering personalised risk information and offering prevention management may reinforce a one-sided focus on personal responsibility, ${ }^{12}{ }^{14}$ directing attention away from (possibly equally important) societal factors for ill health.

\section{Beyond 'personalised' responsibility}

How to determine whether a person is responsible for an action or an omission in the sense for which an individual might be held accountable? The following aspects have been discussed as important within the standard model of responsibility in the context of healthcare: the conditions of knowledge, causality and control or voluntariness. ${ }^{14} 3031 \mathrm{vi}$ According to the standard model, an individual should have access to relevant information, be aware of a causal relationship between behaviour and effect, and free to act as they did (in the absence of controlling influences). ${ }^{14}$ If these conditions are met, a person may be held accountable for their choices and/or actions, and may be treated differently and/or blamed.

Personal responsibility has often been interpreted and applied as a retrospective or backward-looking notion: 'when, under what conditions, is it proper to blame someone for a certain action or a certain outcome? ${ }^{32}$ To attribute retrospective responsibility is equivalent to holding someone accountable for something. Applying retrospective responsibility in the context of epigenetic screening would amount to the question whether the conditions of knowledge/awareness, causality and voluntariness have been fulfilled. ${ }^{14}$ Suppose that an epigenetic test indeed would be able to show that past behaviour and lifestyle of an individual have led to an increased risk of cancer: should we hold that person responsible for their increased risk? It seems the answer should be 'yes', if he/she were aware of the consequences of her lifestyle, his/her lifestyle is causally related to a significant degree to cancer risk and his/her health behaviour was not determined by controlling influences.

Several authors, however, argued that applying a retrospective responsibility raises serious problems. First of all, it is difficult and perhaps even impossible to identify causality; the complex correlations between lifestyle, environmental factors and epigenetic markers, and their causal role in contributing to a specific type of cancer (risk) are yet to be proven. ${ }^{14}$ Moreover, epigenetic changes may also be due to the internal cellular environment and implicate genetic variations. Disentangling the precise causal role of individual lifestyle-related, genetic and environmental factors in the aetiology of disease is currently not (yet) feasible. ${ }^{33}$ For example, a specific epigenetic marker could have been triggered by in utero exposure to a certain toxin and the same marker could have also been triggered by voluntarily getting exposed to this toxin as an adult. Second, it is difficult to establish whether someone has had sufficient control over her behaviour and lifestyle. ${ }^{3034}$ Are unhealthy eating and living patterns caused by

\footnotetext{
${ }^{\mathrm{vi}}$ This conception is in line with what Nicole Vincent classifies as outcome responsibility and what Fischer and Ravizza call moral responsibility. ${ }^{45}$
} 
a voluntary, well-considered choice or by poverty and/or lack of health literacy and capabilities? It is hardly possible to trace whether unhealthy lifestyles are the result of well-considered, voluntary choices or are driven by structural socioeconomic factors or, more likely, a mixture of both. With its focus on causality and the individual, a retrospective concept of moral responsibility may create a tendency to neglect or overlook structural factors. ${ }^{12} 14$

A prospective or forward-looking account of responsibility has thus been proposed to avoid the above-mentioned problems. ${ }^{1430}$ Whereas retrospective responsibility relates to what we have done or neglected to do in the past and integrates causality with culpability and blame, prospective responsibility focusses on the question who is supposed to do what in the (near) future, for example, change health behaviour or pay a higher health insurance premium. ${ }^{35}$ vii To attribute prospective responsibility to someone is comparable to saying that he/she has a moral obligation or duty to, for example, maintain a healthy lifestyle. Whereas retrospective responsibility tends to overlook structural factors, prospective responsibility, on the other hand, emphasises those factors by asking the question: 'who is capable of doing something about it?' This is an essential aspect of (moral) responsibility. Before individuals can be held responsible, they should be enabled to become responsible. ${ }^{30}$ From this point of view, one could argue that other parties than individuals-corporations, international organisations, governmental bodies and the state-are more able to deal with factors harmful to human health. Moreover, governmental bodies and the state should support those groups with less health literacy skills to become capable of attaining a healthy lifestyle. Prospective responsibility therefore meets our concerns about inequality of opportunities.

However, prospective responsibility does not meet all our concerns. What if someone voluntarily and deliberately chooses not to participate in epigenetic screening? Or, what if she takes the test, identified to be at high-risk but does not want to take the advised preventive measures? Are moral sanctions, such as resentment and blame, justified in these cases? Should we hold her responsible and keep her from using collectively funded healthcare resources? The answer might be in the affirmative if we reason from prospective responsibility. After all, if she has the knowledge, skills and adequate support, and thus is really capable of making decisions and adjusting her health behaviour, we may argue that she has an obligation to be healthy, supplemented by blame and/or sanctions.

Individuals may refuse screening or preventive interventions based on their view on the good life: for example, they may not consider health to be the most important value in their lives. These persons may therefore have made an autonomous decision not to participate in screening and prevention. Within both a retrospective and a prospective understanding of personal responsibility, these people can be held responsible for the adverse outcomes of their lifestyle choices. While these people are responsible, this does not imply that we are justified in treating them differently, for example, to blame them, to apply pressure, to increase the premium on his/her insurance company for life insurance or the standard health insurance package, or as an extreme measure, to exclude him/her from healthcare insurance. ${ }^{36}$ There may be good reasons to abstain from moral sanctioning of people even if they fulfil the conditions of the

\footnotetext{
${ }^{\text {vii }}$ Retrospective responsibility (to be held accountable) might be imposed if an individual/a party failed to discharge their prospective responsibility. But also here causality as a condition should be fulfilled. See also Dupras et $a l^{15}$ and Van der Poel. ${ }^{32}$
}

retrospective and/or prospective notion of responsibility. There are (at least two) valid reasons to not impose sanctions.

First, in pluralistic and democratic societies, it is generally acknowledged that citizens should be free to develop ways of life in accordance with their (differing) personal values. After all, people hold different views of the good life. This might imply that people should be able to develop a way of life in which health is not the most important value. As Verweij states, holding a view to take life as it comes is not irrational:

in a pluralistic and democratic society, it is undesirable if particular reasonable ways of life cannot flourish. It is not irrational for a person 'just to live her life' and only bother about her health if she would feel ill or if there are apparent and clear risks. Yet the more one is confronted with offers of screening and preventive care, the more difficult it is to develop and sustain such an attitude. ${ }^{37}$

Moreover, when there is a trade-off of pros and cons as is the case for population-based screening, respect for autonomy is essential. Society can only be pluralistic if it remains possible to choose other ways of life. If certain lifestyles are sanctioned, a voluntary choice is more difficult to make. ${ }^{30}$ It may become difficult to sustain a life in which one only bothers about one's health when one falls ill, if one is punished for this lifestyle, for example, by being withheld from basic healthcare when one does fall ill. When it becomes (too) costly (or dangerous) to live one's life according to one's values, one's autonomy is violated. Genuine freedom presupposes solidarity (in the sense of access to (collectively funded) basic healthcare).

Second, how individuals should be treated is not simply and solely dependent on the question whether an individual is personally responsible (ie, they were knowledgeable and in control) but in the end is determined by the values and purposes of societal institutions. In a welfare state, citizens have collective duties based on the values and purposes of societal institutions; in this case of healthcare institutions and medicine, it is the moral obligation of the healthcare system to care for the sick. It would be tantamount to cruelty to not treat people who suffer from illnesses even if they have led unhealthy lifestyles that in all likelihood have contributed to a disease. People who have refused to be vaccinated against measles are treated nonetheless when they become infected. People who suffer from diseases caused by smoking, sexual transmitted diseases or accidents by wearing no helmets are treated when they fall ill or become injured. ${ }^{\text {viii }}$ This is not a justification for their unhealthy behaviour or a denial of some form of responsibility; it is what a civilised society does when confronted with human suffering. This reasoning is in line with what Mounk calls the institutional account of responsibility. "In deciding what kind of expectations to place on our fellow citizens, we need to decide about the goals the institution of responsibility is meant to serve: What values do ascriptions of responsibility further? What is their relative priority? And how might our decision to place, or not place particular expectations on citizens incentivise actions that are conducive or detrimental to those values?"(36:194) Healthcare as an institution is set up to serve certain values deemed important in society. Meeting healthcare needs is valued because health is necessary to participate in communities and society, to pursue a career, to realise one's ambitions and so on. Whether or not and which type of

\footnotetext{
${ }^{\text {viii }}$ Whether, for example, a higher premium is justified may be answered by asking whether following an unhealthy lifestyle amounts to an unreasonable risk. This approach is suggested by Julian Savulescu. ${ }^{30}$
} 
moral sanctions are justified is dependent on the purposes and values of healthcare which may also include 'practical reasons' (eg, after all, moral sanctions may sometimes exacerbate diseases and increase costs).

The standard model of responsibility thus falls short when determining what sanctions are morally acceptable. The justifiability of moral sanctions is not determined by the attribution of (either a retrospective or a prospective notion of) responsibility, but is constrained by other values held within societies, such as autonomy on the one hand and meeting healthcare needs on the other hand. Even if a person can be held responsible (prospectively or retrospectively), it may still not be acceptable to impose moral sanctions. To determine the moral acceptability of sanctions, moral and practical considerations are important, including the type or level of moral sanctions.

A more promising approach may be the institutional account of responsibility, which places the onus of responsibility for health on institutions rather than individuals and fits with epigenetics. Epigenetic information may help to identify societal or institutional causes of ill health and shift responsibility for health from the individual to states or other institutional actors. ${ }^{38}$

\section{Points to consider for epigenetic risk-predictive cancer screening}

Implementation of epigenetic risk-predictive tests in populationbased screening can only be morally acceptable by taking seriously people's varying health literacy, and social and economic situations. ${ }^{12}$ Personalised medicine is now primarily based on biological differences (differences on molecular, cellular and organ levels). But it should take into account people's health literacy, and social and economic situation in order to be really personalised. Individuals differ in their ability to attain and maintain a healthy lifestyle. Moreover, individuals differ in their views on the good life, including the value of health. In our view, these 'unique' individual differences in social and economic status, in personal identity as well as values and views on the good life, have to be taken seriously. The above discussion on personal responsibility gives rise to the following points to consider for a responsible implementation of epigenetic riskpredictive population-based screening programmes.

First, if people are to reap the benefits of such screening programmes, they must have the opportunity to change their behaviour in response to learning about an increased risk of disease. If the utility of the epigenetic risk-predictive test is proven, implementation is only warranted if offered with adequate support to make decisions and to adopt healthier lifestyles. This means that governments should invest in educational programmes to improve health literary skills across the population and especially target the disadvantaged groups. However, the conditions that must be present to achieve a healthy lifestyle transcend the provision of education; people with a low socioeconomic status must also have the financial means, capacity and opportunity to acquire healthy food and achieve a healthy lifestyle.

Second, an adequate support system can only function properly if based on solid psychological research on the effects of personal risk information on people's motivation to adjust their lifestyle, and on adequate support programmes to assist individuals in changing their lifestyle.

Third, in order for a screening programme to redress the concerns about personal responsibility, the question about personal responsibility and the question about moral sanctions should be clearly distinguished. The question of responsibility is often directly linked to how people should be treated and whether people are still entitled to care or for reimbursement of care. These are, however, two different questions. ${ }^{36}$ Discussions around screening for risks and the availability of preventive measures often end up in this misunderstanding. Because some people do not want persons who are responsible to be blamed, or to pay a higher health insurance premium, they start arguing that those persons are not responsible (they could not do anything about it). ${ }^{\text {ix }}$ But even if that was the case (ie, they could (have) do(ne) something about it), there are moral (solidarity) and practical reasons to abstain from moral sanctions.

Finally, if the validity of epigenetic risk-predictive tests is proven, implementation in population-based screening should start on a small scale by including, at first, a learning phase to develop the system gradually in an iterative way.

Since epigenetic screening will have a profound impact on participants, non-participants and the organisation of population screening programmes, a responsible and sustaining implementation requires a careful and cautious approach with ample time to evaluate the technology and the experiences of participants of screening programmes as well as individuals who refuse or do not take part in screening, and to enable a public debate. This evaluation needs to pay special attention to the effects of implementing epigenetic screening in a society on the tendency within societies to hold individuals responsible for their health.

\section{CONCLUSION}

Given the special salience of epigenetic biomarkers, linking environmental and lifestyle factors to individuals' risks of cancer, the (future) introduction of epigenetics-based screening programmes raises questions regarding personal responsibility for health. It is not unimaginable that if epigenetic biomarkers allow for real-time monitoring of risk status and expose traceable relationships between lifestyle factors and disease risks, individuals will increasingly be held responsible for ill health and subject to moral sanctioning. To assess the justifiability of moral sanctions, however, the standard model of (retrospective or prospective) personal responsibility does not provide sufficient normative guidance. Other values, such as autonomy and society's duty to relieve human suffering, will likely be more important. Moreover, institutional accounts of responsibility may be more suitable, as they reflect the presence of causal factors of ill health that may be beyond individual control. This paper offers some points to consider for those who will be involved in the setting up of epigenetics-based screening programmes in relation to personal responsibility.

Contributors IB and EMB drafted the manuscript and KT, NP, MW and IdB offered substantial contributions to the conception of the work and critically revised it for important intellectual content.

Funding The authors' research is supported by the European Union's Horizon 2020 Programme (H2020/2014-2020) under grant agreement number 634570) and the Netherlands Organisation of Scientific Research (NWO) within the Responsible Innovation (MVI) (grant no. 313-99-332).

Competing interests UCLB (UCL's commercialisation company) has filed patents on DNA methylation and risk prediction on which Martin Widschwendter is named as an inventor.

Patient consent for publication Not required.

Provenance and peer review Not commissioned; externally peer-reviewed. Data availability statement There are no data in this work.

\footnotetext{
${ }^{\text {ix }}$ Mounk calls it 'the denial of responsibility': as a response to right-wing politics, left-wing politicians did not contest the value of personal responsibility but argued that people are unable to bear responsibility. ${ }^{36}$
} 
Open access This is an open access article distributed in accordance with the Creative Commons Attribution Non Commercial (CC BY-NC 4.0) license, which permits others to distribute, remix, adapt, build upon this work non-commercially, and license their derivative works on different terms, provided the original work is properly cited, appropriate credit is given, any changes made indicated, and the use is non-commercial. See: http://creativecommons.org/licenses/by-nc/4.0/.

\section{REFERENCES}

1 Flores M, Glusman G, Brogaard K, et al. P4 medicine: how systems medicine will transform the healthcare sector and society. Per Med 2013;10(6):565-76.

2 Roadmap Epigenomics Consortium, Kundaje A, Meuleman W, et al. Integrative analysis of 111 reference human epigenomes. Nature 2015;518(7539):317-30.

3 Goldberg AD, Allis CD, Bernstein E. Epigenetics: a landscape takes shape. Cell 2007:128(4):635-8.

4 Widschwendter M, Jones A, Evans I, et al. Epigenome-based cancer risk prediction: rationale, opportunities and challenges. Nat Rev Clin Oncol 2018;15(5):292-309.

5 Jirtle RL, Skinner MK. Environmental epigenomics and disease susceptibility. Nat Rev Genet 2007;8(4):253-62.

6 Verma M, Khoury MJ, loannidis JPA. Opportunities and challenges for selected emerging technologies in cancer epidemiology: mitochondrial, epigenomic, metabolomic, and telomerase profiling. Cancer Epidemiol Biomarkers Prev 2013:22(2):189-200.

7 Smith ZD, Meissner A. Dna methylation: roles in mammalian development. Nat Rev Genet 2013;14(3):204-20.

8 Chatterjee A, Rodger EJ, Eccles MR. Epigenetic drivers of tumourigenesis and cancer metastasis. Semin Cancer Biol 2018;51:149-59.

9 Alblas M, Schermer M, Vergouwe Y, et al. Autonomy challenges in (epi)genetic riskstratified cancer screening: a framework to guide the development of patient decision aids and support informed consent. Pers Med 2019;9(1).

10 Joly Y, So D, Saulnier K, et al. Epigenetics ELSI: darker than you think? Trends Genet 2016;32(10):591-2.

11 Schermer MHN, Richard E. On the reconceptualization of Alzheimer's disease. Bioethics 2019:33(1):138-45.

12 Prainsack B. Precision medicine needs a cure for inequality. Curr Hist 2019;118(804):11-15.

13 Vears DF, D'Abramo F, Health AF. Health, wealth and behavioural change: an exploration of role responsibilities in the wake of epigenetics. J Community Genet 2018:9(2):153-67.

14 Hedlund M. Epigenetic responsibility. Med Stud 2012;3:171-83.

15 Dupras C, Ravitsky V. The ambiguous nature of epigenetic responsibility. J Med Ethics 2016;42(8):534-41.

16 Huang JY, King NB. Epigenetics changes nothing: what a new scientific field does and does not mean for ethics and social justice. Public Health Ethics 2018;11(1):69-81.

17 Pashayan N, Guo Q, Pharoah PDP. Personalized screening for cancers: should we consider polygenic profiling? Per Med 2013;10(6):511-3.

18 Rebitschek FG, Reisel D, Lein I, et al. Epigenetic risk assessment of female cancers: women's information needs and attitudes. Public Health Genomics 2019;22(12):46-57.

19 Park HL. Epigenetic biomarkers for environmental exposures and personalized breast cancer prevention. Int J Environ Res Public Health 2020;17(4):1181.

20 Bollepalli S, Kaye S, Heinonen S, et al. Subcutaneous adipose tissue gene expression and DNA methylation respond to both short- and long-term weight loss. Int I Obes 2018;42(3):412-23.

21 Noreen F, Röösli M, Gaj P, et al. Modulation of age- and cancer-associated DNA methylation change in the healthy colon by aspirin and lifestyle. J Natl Cancer Inst 2014;106(7). doi:10.1093/jnci/dju161. [Epub ahead of print:

22 Marteau TM, French DP, Griffin SJ, et al. Effects of communicating DNA-based disease risk estimates on risk-reducing behaviours. Cochrane Database Syst Rev 2010;6(10).
23 Hollands GJ, French DP, Griffin SJ, et al. The impact of communicating genetic risks of disease on risk-reducing health behaviour: systematic review with meta-analysis. BMJ 2016;352.

24 French DP, Cameron E, Benton JS, et al. Can communicating personalized disease risk promote health behaviour. Ann Behav Med 2017;5:718-29.

25 Sørensen K, Pelikan JM, Röthlin F, et al. Health literacy in Europe: comparative results of the European health literacy survey (HLS-EU). Eur J Public Health 2015;25(6):1053-8.

26 UCL Institute of Health Equity. Local action on health inequalities. improving health literacy to reduce health inequalities. public health England, 2015. Available: http:// www.healthliteracyplace.org.uk/media/1239/hl-and-hi-ucl.pdf [Accessed 1012 2019].

27 Marmot M, Bell R. Fair Society, healthy lives. Public Health 2012;126 Suppl 1(1):S4-10.

28 Wegwarth O, Pashayan N, Widschwendter M, et al. Women's perception, attitudes, and intended behavior towards predictive epigenetic risk testing for female cancers in 5 European countries: a cross-sectional online survey. BMC Public Health 2019;19(1):667.

29 Dupras C, Song L, Saulnier KM, et al. Epigenetic discrimination: emerging applications of epigenetics pointing to the limitations of policies against genetic discrimination. Front Genet 2018;9:202.

30 Savulescu J. Golden opportunity, reasonable risk and personal responsibility for health. J Med Ethics 2018;44(1):59-61.

31 Glannon W. Responsibility and priority in liver transplantation. Camb Q Healthc Ethics 2009:18(1):23-35.

32 van de Poel I. The Relation Between Forward-Looking and Backward-Looking Responsibility. In: Vincent NA, van de Poel I, van den Hoven J, eds. Moral responsibility. Dordrecht: Springer, 2011: 37-52.

33 Chiapperino L. Epigenetics: ethics, politics, biosociality. Br Med Bull 2018;128(1):49-60.

34 Friesen P. Personal responsibility within health policy: unethical and ineffective. J Med Ethics 2018;44(1):53-8.

35 ten Have H. Paper one: the distinction between prospective and retrospective responsibility. Health Care Anal 1994;2:119-23.

36 Mounk Y. The Age of Responsibility. Luck, Choice and the Welfare State. Harvard University Press, 2017.

37 Verweij MF. Preventing Disease. In: Ashcroft R, Dawson A, Draper $\mathrm{H}$, et al, eds. Principles of Health Care Ethics second edition Wiley. Chichester, 2007: 557-62.

38 Dupras C, Saulnier KM, Joly Y. Epigenetics, ethics, law and society: a multidisciplinary review of descriptive, instrumental, dialectical and reflexive analyses. Soc Stud Sci 2019;49(5):785-810

39 Illum LRH, Bak ST, Lund S, et al. Dna methylation in epigenetic inheritance of metabolic diseases through the male germ line. J Mol Endocrinol 2018;60(2):R39-56.

40 Ismaili M'hamdi H, Hilhorst M, Steegers EAP, et al. Nudge me, help my baby: on otherregarding nudges. J Med Ethics 2017;43(10):702-6.

41 Hofmann B. Medicalization and overdiagnosis: different but alike. Med Health Care Philos 2016;19(2):253-64.

42 Pashayan N, Morris S, Gilbert FJ, et al. Cost-Effectiveness and Benefit-to-Harm ratio of risk-stratified screening for breast cancer: a life-table model. JAMA Oncol 2018;4(11):1504-10

43 Callender T, Emberton M, Morris S, et al. Polygenic risk-tailored screening for prostate cancer: a benefit-harm and cost-effectiveness modelling study. PLoS Med 2019;16(12):e1002998

44 Hofmann B, Skolbekken JA, Getz L. The name of the game: Is preventive screening "cancer screening?". Eur J Clin Invest 2019;49(6):e13096.

45 Vincent NA. A Structured Taxonomy of Responsibility Concepts. In: Vincent NA, der Pvan I, Hoven van der J, eds. Moral responsibility. beyond free will and responsibility. Springer Science Business Media B.V, 2011: 15-35. 